\title{
Thrombocytosis is associated with increased short and long term mortality after exacerbation of chronic obstructive pulmonary disease: a role for antiplatelet therapy?
}

\author{
Michelle T Harrison, ${ }^{1}$ Philip Short, ${ }^{1,2}$ Peter A Williamson, ${ }^{1,3}$ Aran Singanayagam, ${ }^{4}$ \\ James D Chalmers, ${ }^{1,2}$ Stuart Schembri ${ }^{1}$
}

\begin{abstract}
${ }^{1}$ Tayside Respiratory Research Group, Ninewells Hospital and Medical School, Dundee, UK

${ }^{2}$ University of Dundee, Dundee, UK

${ }^{3}$ Perth Royal Infirmary, Perth, UK

${ }^{4}$ Imperial College London, London, UK
\end{abstract}

\section{Correspondence to} Dr Michelle Harrison, Tayside Respiratory Research Group, Ninewells Hospital and Medical School, Dundee DD1 9SY, UK; michelleharrison1@nhs.net

Received 14 June 2013 Revised 4 March 2014 Accepted 26 March 2014

Published Online First 17 April 2014

\section{SLinked}

- http://dx.doi.org/10.1136/ thoraxjnl-2014-205329

\section{CrossMark}

To cite: Harrison MT, Short $\mathrm{P}$, Williamson $\mathrm{PA}$, et al. Thorax 2014;69: 609-615.

\section{ABSTRACT}

Introduction Evidence suggests that platelets play a significant role in inflammation in addition to their role in thrombosis. Systemic inflammation is linked to poor short and long term outcomes in COPD. Increased platelet activation has been reported in acute exacerbations of COPD (AECOPD). We investigated whether thrombocytosis is independently associated with poor outcomes following AECOPD.

Methods An observational cohort study of patients hospitalised with AECOPD was performed. Patients were $>40$ years with spirometry confirmed COPD admitted between 2009 and 2011. Platelet count was recorded on admission. The primary outcome was 1-year all-cause mortality. Secondary outcomes included inhospital mortality and cardiovascular events. Analyses were conducted using logistic regression after adjustment for confounding variables.

Results 1343 patients (49\% male) were included. Median age was 72 years (IQR 63-79 years). 157 $(11.7 \%)$ had thrombocytosis. Thrombocytosis was associated with both 1-year mortality and inhospital mortality; OR $1.53(95 \% \mathrm{Cl} 1.03$ to $2.29, \mathrm{p}=0.030)$ and OR 2.37 (95\% Cl 1.29 to $4.34, p=0.005)$, respectively. Cardiovascular hospitalisation was not significantly increased (OR $1.13(95 \% \mathrm{Cl} 0.73$ to $1.76, p=0.600))$ in patients with thrombocytosis. Aspirin or clopidogrel treatment correlated with a reduction in 1-year mortality (OR $0.63(95 \% \mathrm{Cl} 0.47$ to $0.85, p=0.003)$ ) but not inhospital mortality (OR $0.69(95 \% \mathrm{Cl} 0.41$ to 1.11 , $\mathrm{p}=0.124)$ ).

Conclusions After adjustment for confounders thrombocytosis was associated with increased 1-year mortality after exacerbation of COPD. Antiplatelet therapy was associated with significantly lower 1-year mortality and may have a protective role to play in patients with AECOPD.

\section{INTRODUCTION}

COPD is a systemic disorder associated with increased risk of cardiovascular disease, diabetes and hypertension. ${ }^{1-3}$ Systemic inflammation is a key driver of cardiovascular disease in COPD. ${ }^{4}$ In addition to haemostasis and thrombosis, ${ }^{6}$ platelets are proposed as key inflammatory mediators. ${ }^{78}$ Platelets granules store and secrete a number of bioactive substances which are released upon platelet activation. This results in platelet aggregation, neutrophil and

\section{Key messages}

What is the key question?

- Is thrombocytosis an independent marker of poor outcome following acute exacerbation of COPD and do antiplatelet therapies improve outcome?

What is the bottom line?

- Thrombocytosis is independently associated with increased inhospital and 1-year all-cause mortality, and antiplatelet therapy is associated with reduced 1-year all-cause mortality following acute exacerbation of COPD.

\section{Why read on?}

- Thrombocytosis is an accessible, independent predictor of short term and 1-year mortality in acute exacerbations of COPD, and antiplatelet therapy may be associated with a survival benefit.

monocyte adhesion, chemotaxis, cell survival and proliferation, coagulation and proteolysis. ${ }^{8}$

Few studies examine the role of platelets in COPD. In murine models, acute hypoxia has been associated with thrombocytosis. ${ }^{9}$ Similarly, platelet volume and aggregation are increased in hypoxaemic, stable COPD. ${ }^{10}{ }^{11}$ Platelet-monocyte aggregates are a sensitive marker of platelet activation, and are increased in patients with COPD, with further increases during acute exacerbations of COPD (AECOPD). ${ }^{12}{ }^{13}$ With evidence for the pro-inflammatory properties of platelets, and given that COPD is associated with cardiovascular disease, ${ }^{14-16}$ studies have proposed antiplatelet therapy in COPD. ${ }^{13} 16$ To date, there have been no randomised trials in patients with COPD and there are no studies investigating antiplatelet therapy after AECOPD. We hypothesised that thrombocytosis in patients with AECOPD would be associated with increased short and long term mortality. We also tested the hypothesis that antiplatelets may have a protective role to play in patients with AECOPD. 


\section{METHODS}

\section{Study database}

This study describes a secondary analysis of the EXODUS cohort (EXacerbations of Obstructive lung Disease managed in UK Secondary care), a multicentre audit database. The database prospectively included patients admitted to 12 hospitals with AECOPD $^{17}$ and was approved by the South East Scotland research ethics committee and local Caldicott guardians. Participants were $\geq 40$ years admitted for $>12 \mathrm{~h}$ from June 2009 to December 2011. Inclusion criteria were: primary diagnosis of AECOPD and a diagnosis of COPD confirmed by spirometry when stable. Exclusion criteria were age $<40$ years, airways disease primarily due to other cause (community-acquired pneumonia, ILD, asthma, bronchiectasis), suspected or proven alternative diagnosis for the deterioration in symptoms (heart failure, $\mathrm{PE}$ or pneumonia on chest X-ray), transfers from other hospitals, and patients in whom active treatment was not considered appropriate (palliative care).

\section{Study data}

Demographics and medication records were obtained on admission from patient histories using standard hospital clerk-in pro formas. Laboratory and radiology results included were the first tests from admission. Medications recorded included all COPD and cardiovascular medications. Patients using aspirin or clopidogrel on admission to hospital were recorded as 'antiplatelet users'. Severity of COPD was classified according to the Medical Research Council (MRC) dyspnoea score, \% predicted $\mathrm{FEV}_{1}$ and the Global Initiative for Chronic Obstructive Lung Disease (GOLD) 2011 staging system. ${ }^{18}$ Missing data were assumed to be normal for the purposes of analysis.

Readmission and postdischarge data were identified from hospital records and morbidity databases using International Classification of Diseases, 10th revision (ICD-10) codes. Data were obtained for 12 months after discharge, and therefore follow-up was completed in December 2012. Patients were entered into the database once, readmissions being recorded as such rather than a new entry.

Laboratory variables including platelet count, white blood cell count and $\mathrm{C}$ reactive protein (CRP) were measured according to local protocol with no significant differences in mean platelet counts between hospitals (data not shown). Patients were categorised into three groups for analysis according to platelet count: normal platelet count range; $150-400 \times 10^{9} \mathrm{cells} / \mathrm{mm}^{3}$, thrombocytopenia; platelets $<150 \times 10^{9}$ cells $/ \mathrm{mm}^{3}$ and thrombocytosis; $>400 \times 10^{9}$ cells $/ \mathrm{mm}^{3}$.

\section{Outcomes}

The primary outcome is 1-year mortality, analysed as death from the first day of admission to completion of 1-year follow-up. Secondary outcomes were inhospital mortality and postdischarge mortality (from discharge until 1-year follow-up). Cardiovascular events and cardiovascular mortality were also recorded. Death certification data were used to identify all deaths. Validity of the data was confirmed by manual review of medical records at two sites. ICD 10 codes were used to identify mortality and readmissions due to cardiovascular causes: I20-23 (acute myocardial infarction and acute coronary syndromes including unstable angina), I50 (cardiac failure incorporating congestive cardiac failure (I50.0) and left ventricular failure (I50.1)), I46 (cardiac arrest and cardiac arrhythmia), I44 (atrioventricular disorders), I45 (other conduction disorders), I47 (paroxysmal tachycardia), I48 (atrial fibrillation and flutter) and I49 (other cardiac arrhythmias).

\section{Statistical analysis}

Continuous variables were assessed for normality using D'Agostino's $\mathrm{K}^{2}$ test. Categorical variables in tables 1 and 2 were compared between the three platelet groups using the $\chi^{2}$ test. As continuous data in tables 1 and 2 were found to be nonparametric, these data were compared using the Kruskal-Wallis test. Correlations of platelet count with CRP and white blood cell count were performed using simple linear regression. Cumulative survival was determined by the Kaplan-Meier method and compared using the log-rank test.

\section{Logistic regression analysis}

Logistic regression was used to generate ORs for the association between thrombocytosis or antiplatelet therapy with mortality. For the primary logistic regression analysis, covariates were selected based on clinical assessment of the likelihood of confounding and retained in the final model if they remained significant at $p<0.05$ or were found to modify the OR by at least $10 \%$ when included in a model with the main exposure variable. Selected variables for the analysis of thrombocytosis were age (continuous), gender (male $=1 /$ female $=0$ ), residence in long term care (yes/no), history of myocardial infarction (yes/no), stable angina (yes/no), coronary artery bypass grafting (yes/no), stroke (yes/no), congestive cardiac failure (yes/no), neoplastic disease (yes/no), diabetes (yes/no), current use of antiplatelet drugs (yes/no), Body Mass Index (continuous), $\mathrm{FEV}_{1} \%$ predicted (continuous), MRC dyspnoea score (continuous), use of long term oxygen therapy (LTOT) (yes/no), current cigarette smoking (yes/no), $\mathrm{P}_{\mathrm{a}} \mathrm{CO}_{2}$ (continuous), acidosis (yes/no), $\mathrm{PaO}_{2}$ to $\mathrm{FiO}_{2}$ ratio (continuous) and severity of exacerbation using the BAP-65 (blood urea nitrogen $>25 \mathrm{mg} / \mathrm{dL}$, altered mental status, pulse $>109$ beats/min, age $>65$ years) severity index, a validated COPD exacerbation index. ${ }^{19}$ In addition, for the analysis of antiplatelet therapies effect, modification of use of $\beta$-blockers (yes/no), statins (yes/no), ACE inhibitors (yes/no) and anticoagulants (yes/no) was tested. The Hosner-Lemeshow goodness of fit test was used to assess model adequacy. The data are reported in accordance with STROBE guidance.

A $p<0.05$ was considered statistically significant for all analyses. All data were analysed using SPSS V.21 for windows.

\section{RESULTS}

A total of 1698 unique records were entered into EXODUS; 355 were excluded, primarily due to inclusion more than once $(n=131)$ or loss to follow-up where data could not be verified with long term follow-up data (figure 1).

Overall, 1343 patients (49\% male) were included in the study. Demographics, COPD severity, comorbidities and medication use are shown (table 1). Of the cohort, $85.4 \%$ of patients had a normal platelet count (median platelets $243 \times 109$ cells $/ \mathrm{mm}^{3}$, IQR $199-299 \times 109$ cells $/ \mathrm{mm}^{3}$ ), $2.9 \%$ were thrombocytopenic (117, IQR 97-141×109 cells $/ \mathrm{mm}^{3}$ ) and $11.7 \%$ had thrombocytosis $\left(474\right.$, IQR $433-547 \times 109$ cells $\left./ \mathrm{mm}^{3}\right)$ on admission. As the thrombocytopenia group was small, no further analysis was performed but data are shown (tables 1 and 2). There was no difference in GOLD class between the groups (table 1). Other recognised markers of severity were more common in the thrombocytosis group compared with the normal group, with higher frequency of exacerbations in the previous year (mean $1.42 \mathrm{SD} 1.9$ vs mean $1.1 \mathrm{SD} 1.8, \mathrm{p}=0.0240$ ), a lower median albumin (34 g/L IQR 31-38 vs $37 \mathrm{~g} / \mathrm{L} 33-40, \mathrm{p}<0.0001)$ and 
Table 1 Demographic data

\begin{tabular}{|c|c|c|c|c|c|}
\hline & Overall study cohort & $\begin{array}{l}\text { Thrombocytopenia } \\
<150 \times 10^{9} \text { cells } / \mathrm{mm}^{3}\end{array}$ & $\begin{array}{l}\text { Thrombocytosis } \\
\left(>400 \times 10^{9} \text { cells } / \mathrm{mm}^{3}\right)\end{array}$ & $\begin{array}{l}\text { Normal Platelets } \\
\left(150-400 \times 10^{9} \text { cells } / \mathrm{mm}^{3}\right)\end{array}$ & p Value \\
\hline \multicolumn{6}{|l|}{ Demographics and major comorbidities } \\
\hline $\mathrm{N}$ & 1343 & 39 & 157 & 1147 & \\
\hline Age (median and IQR) & $72(63-79)$ & $66(59-75)$ & $72(63-79)$ & $72(63-80)$ & 0.058 \\
\hline Male gender & $655(49)$ & $17(44)$ & $63(40)$ & $572(50)$ & 0.060 \\
\hline Active smokers & $448(33)$ & $12(31)$ & $44(28)$ & 392 (34) & 0.291 \\
\hline Previous myocardial infarction & $377(28)$ & $8(21)$ & $48(31)$ & $321(28)$ & 0.451 \\
\hline CABG grafting & $70(5)$ & $1(3)$ & $10(6)$ & $59(5)$ & 0.610 \\
\hline Angina & $188(14)$ & $4(10)$ & $20(13)$ & $164(14)$ & 0.689 \\
\hline Previous stroke & $195(15)$ & $4(10)$ & $20(13)$ & $171(15)$ & 0.573 \\
\hline Renal failure & $115(9)$ & $4(10)$ & $14(9)$ & $97(8)$ & 0.912 \\
\hline Diabetes & $203(15)$ & $6(15)$ & $21(13)$ & $176(15)$ & 0.811 \\
\hline Previous neoplastic disease & $171(13)$ & $2(5)$ & $20(13)$ & $149(13)$ & 0.350 \\
\hline \multicolumn{6}{|l|}{ COPD severity } \\
\hline $\mathrm{FEV}_{1} \%$ predicted (median and IQR) & $46 \%(34 \%-66 \%)$ & $47 \%(38 \%-68 \%)$ & $42 \%(32 \%-65 \%)$ & $47 \%(34 \%-64 \%)$ & 0.598 \\
\hline MRC dyspnoea score (median and IQR) & $4(3-5)$ & $4(3-5)$ & $4(3-5)$ & $4(3-5)$ & 0.430 \\
\hline 2011 GOLD COPD stage & & & & & $0.480^{*}$ \\
\hline A & $118(9)$ & $6(15)$ & $12(8)$ & $100(9)$ & \\
\hline B & $479(36)$ & $14(36)$ & $58(37)$ & $407(35)$ & \\
\hline $\mathrm{C}$ & $93(7)$ & $2(5)$ & $6(4)$ & $85(7)$ & \\
\hline $\mathrm{D}$ & $653(49)$ & $17(44)$ & $81(52)$ & $555(48)$ & \\
\hline Prescribed long term oxygen therapy & $122(9)$ & $2(5)$ & $22(14)$ & $98(9)$ & 0.056 \\
\hline Body Mass Index $\leq 18.5$ & $130(10)$ & $3(8)$ & $23(15)$ & $104(9)$ & 0.037 \\
\hline \multicolumn{6}{|l|}{ Medication } \\
\hline Statins & $566(42)$ & $11(28)$ & $57(36)$ & $498(43)$ & 0.048 \\
\hline ACE inhibitors or angiotensin receptor blockers & $666(50)$ & $15(38)$ & $69(44)$ & $582(51)$ & 0.103 \\
\hline Aspirin & $622(46)$ & $10(26)$ & $62(40)$ & $550(48)$ & 0.003 \\
\hline Clopidogrel & $91(7)$ & $1(3)$ & $12(8)$ & $78(7)$ & 0.527 \\
\hline$\beta$-Blockers & $228(17)$ & $7(18)$ & $28(18)$ & $193(17)$ & 0.939 \\
\hline Warfarin & $98(7)$ & $6(15)$ & $16(10)$ & $76(7)$ & 0.039 \\
\hline ICS & 1047 (78) & $28(72)$ & $118(75)$ & 901 (79) & 0.404 \\
\hline LABA & $1007(75)$ & 27 (69) & $119(76)$ & $861(75)$ & 0.688 \\
\hline LAMA & $1060(79)$ & $35(90)$ & $128(82)$ & 897 (78) & 0.154 \\
\hline
\end{tabular}

lower Body Mass Index (table 1). When comparing thrombocytosis and normal platelet groups (excluding thrombocytopenia), thrombocytosis was significantly associated with male gender $(p=0.02)$, use of LTOT $(p=0.03)$, higher white blood cell count $(p<0.0001)$ (table 2$)$, more frequent acidosis $(p=0.01)$, higher $\mathrm{PaCO}_{2}$ values $(\mathrm{p}=0.008)$, lower $\mathrm{PaO}_{2}$ to $\mathrm{FiO}_{2}$ ratio $(\mathrm{p}=0.0003)$ and more use of non-invasive ventilation $(\mathrm{p}=0.01)$ (table 3).

Length of stay was similar between patients with thrombocytosis (median 5 days, IQR 3-8) and patients with normal platelet count (median 6 days, IQR 3-11) and thrombocytopenia (7 days, IQR 2-11), $\mathrm{p}=0.165$.

\section{The impact of thrombocytosis on mortality and cardiovascular events}

Inpatient mortality was $6.2 \%$ and $18.8 \%$ of patients who survived beyond hospital discharge had died at 1 year. Thrombocytosis was associated with increased mortality over 1-year follow-up (OR 1.53 (95\% CI 1.03 to 2.29, p=0.030)). The logistic regression model and significant covariates predicting 1-year mortality are shown (table 3). These were age, congestive cardiac failure, neoplastic disease, MRC dyspnoea score, LTOT and acidosis during exacerbation, all of which were associated with increased mortality, while antiplatelet therapy was associated with reduced mortality (analysed in more detail below). The Kaplan-Meier survival analysis is shown in figure 2. The difference between the thrombocytosis and normal platelet group was statistically significant by the log-rank test $(p=0.008)$.

Thrombocytosis patients had increased inhospital mortality compared with those with normal platelet counts $(11.5 \%$ vs 4.9\%). In the logistic regression analysis, thrombocytosis was independently associated with increased inhospital mortality (OR 2.37 (95\% CI 1.29 to 4.34, p=0.005)). When considering only events after hospital discharge to 1 year, the OR for mortality for platelet count $>400$ was 1.30 (95\% CI 0.82 to 2.06 , $\mathrm{p}=0.261)$.

Overall, 268 patients (20\%) were hospitalised due to a cardiovascular event during follow-up. These were predominantly hospitalisation associated with congestive cardiac failure (11\%), acute coronary syndromes (5\%), acute myocardial infarction $(4 \%)$ and/or arrhythmias (17\%). Increased 1-year mortality in patients with thrombocytosis could not be attributed solely to 
Table 2 Exacerbation characteristics

\begin{tabular}{|c|c|c|c|c|c|}
\hline & Overall study cohort & Thrombocytopenia & Thrombocytosis & Normal platelets & p Value* \\
\hline \multicolumn{6}{|l|}{ Physiological markers of exacerbation severity } \\
\hline New onset confusion & $161(12)$ & $5(12.8 \%)$ & $18(12)$ & $138(12)$ & 0.967 \\
\hline Heart rate (beats per minute) (median and IQR) & $100(90-120)$ & $105(96-120)$ & $100(90-114)$ & $100(90-120)$ & 0.468 \\
\hline Respiratory rate (breaths per minute) (median and IQR) & $24(20-30)$ & $22(16-30)$ & $24(20-30)$ & $24(20-31)$ & 0.554 \\
\hline Systolic blood pressure (mm Hg) (median and IQR) & $122(105-140)$ & $113(100-134)$ & $123(108-140)$ & $121(105-141)$ & 0.187 \\
\hline Temperature $\left({ }^{\circ} \mathrm{C}\right)$ (median and IQR) & $37(36.8-37.9)$ & $37(36.9-38.0)$ & $37(36.7-37.5)$ & $37(36.8-37.7)$ & 0.204 \\
\hline \multicolumn{6}{|l|}{ Laboratory results } \\
\hline White blood cell count $\left(\times 10^{9}\right.$ cells $\left./ \mathrm{mm}^{3}\right)$ (median and IQR) & $13.6(10-17.8)$ & $11.5(8.2-15.4)$ & $16.2(11.9-20.9)$ & $13.7(10.1-17.8)$ & $<0.0001$ \\
\hline$C$ reactive protein $(\mathrm{mg} / \mathrm{L}$ ) (median and IQR) $\mathrm{N}=913$ & $38(13-74)$ & $27(4-87)$ & $41(21-81)$ & $38(13-74)$ & 0.355 \\
\hline Urea (mmol/L) (median and IQR) & $7.3(5-10.6)$ & $7.5(4.6-10.9)$ & $6.4(4.7-10.2)$ & $7.3(5.1-10.6)$ & 0.601 \\
\hline Acidosis (arterial pH <7.35) & $207(15)$ & $6(15)$ & $35(22)$ & $166(14)$ & 0.039 \\
\hline Glucose (mmol/L) (median and IQR) N=1105 & $6.8(5.7-8.4)$ & $6.3(5.7-8.4)$ & $6.7(5.4-8.1)$ & $6.9(5.8-8.5)$ & 0.276 \\
\hline Albumin (g/dl) & $37(33-40)$ & 37 (33-39) & $34(31-38)$ & $37(33-40)$ & $<0.0001$ \\
\hline $\begin{array}{l}\mathrm{pCO}_{2}(\mathrm{kPa}) \text { (median and IQR) } \\
\mathrm{N}=1046\end{array}$ & $5.8(4.9-6.7)$ & $5.3(4.2-7.0)$ & $6.5(5.4-8.4)$ & $5.7(4.9-6.6)$ & 0.120 \\
\hline $\mathrm{pO}_{2} \mathrm{To}_{\mathrm{FiO}}$ ratio approximation (median and IQR) & $278(218-315)$ & $275(254-307)$ & $265(192-313)$ & $281(220-318)$ & 0.096 \\
\hline \multicolumn{6}{|l|}{ Treatment } \\
\hline Preadmission antibiotics & $226(17)$ & $5(13)$ & $21(13)$ & $200(17)$ & 0.352 \\
\hline Preadmission corticosteroids & $228(17)$ & $9(23)$ & $24(15)$ & $195(17)$ & 0.510 \\
\hline Nebulised bronchodilators & $1343(100)$ & $39(100)$ & $157(100)$ & $1147(100)$ & 1.000 \\
\hline Oral corticosteroids & $1316(98)$ & $37(95)$ & $157(100)$ & $1122(98)$ & 0.070 \\
\hline Antibiotics & $1121(83)$ & $36(92)$ & $139(89)$ & $946(86)$ & 0.051 \\
\hline Intravenous aminophylline & $148(11)$ & $3(8)$ & $24(15)$ & $121(11)$ & 0.164 \\
\hline Bilevel ventilation & $123(9)$ & $3(8)$ & $23(15)$ & $97(9)$ & 0.039 \\
\hline
\end{tabular}

cardiovascular events because there was no statistically significant increase in cardiovascular hospitalisation (OR 1.13 (95\% CI 0.73 to 1.76$), p=0.6$ ). The strongest predictors of cardiovascular hospitalisation in this model were age (OR 1.02 (95\% CI 1.01 to $1.04, \mathrm{p}=0.006)$ ), previous myocardial infarction (OR $2.23(95 \%$ CI 1.55 to $3.21, \mathrm{p}<0.0001)$ ), neoplastic disease (OR 2.00 (95\% CI 1.33 to $3.00, \mathrm{p}=0.0009)$ ), diabetes (OR 1.79 (95\% CI 1.15 to $2.80, \mathrm{p}=0.011)$ ), MRC dyspnoea score (OR $1.69(95 \%$ CI 1.44 to $1.98, \mathrm{p}<0.0001)$ ) and LTOT (OR 2.35 $(95 \%$ CI 1.54 to $3.59, \mathrm{p}<0.0001))$.

\section{Antiplatelets and anticoagulants}

To further investigate the role of platelet function in AECOPD, we studied whether antiplatelet therapy would influence outcomes. A total of $713(53.0 \%)$ patients were using antiplatelet agents. In the Kaplan-Meier analysis, there was no significant relationship between antiplatelet therapy and mortality $(p=0.093$ by log-rank test, figure 2$)$. After adjustment for confounders in the logistic regression analysis (shown in table 4), antiplatelet therapy was associated with reduced overall 1-year mortality after exacerbation of COPD (OR 0.63 (95\% CI 0.47
Figure 1 Flow chart describing the study. $\mathrm{AECOPD}=$ acute exacerbations of COPD. * Patient data were rejected if they contained clear inaccuracies that could not be resolved with the researchers or lacked an accurate identification code to enable record linkage for determining outcomes (therefore classified as lost to follow-up).

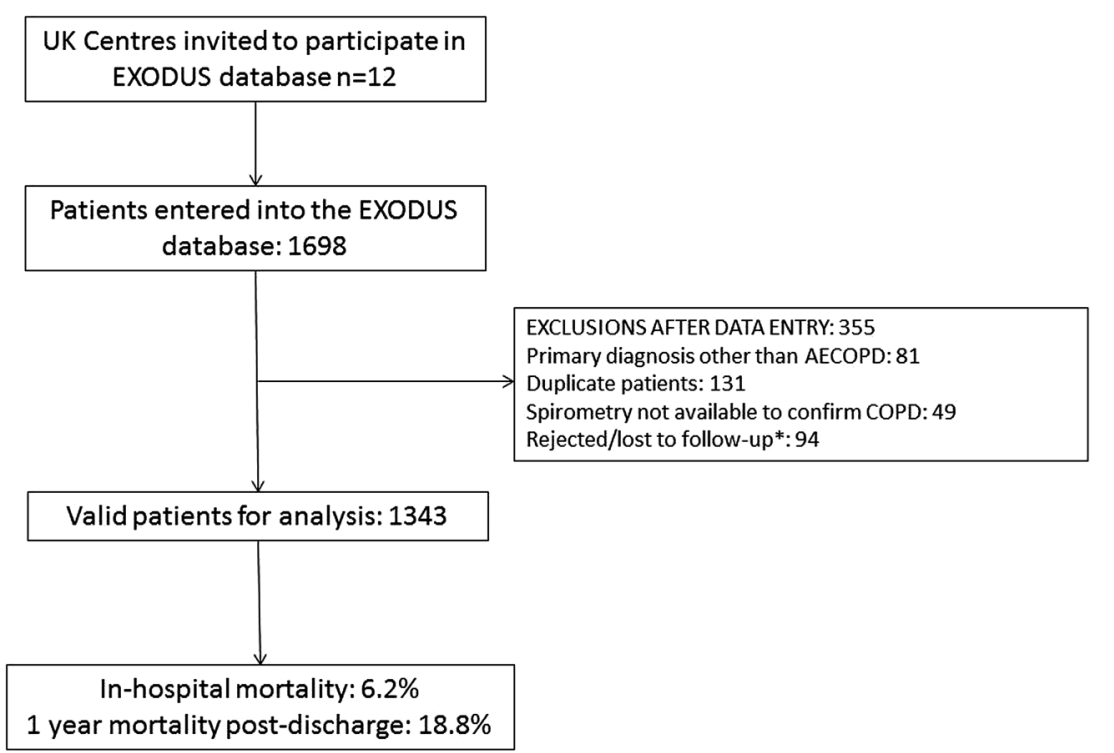


Table 3 Thrombocytosis and outcomes: logistic regression analyses

\begin{tabular}{|c|c|c|c|}
\hline Predictor & OR & $95 \% \mathrm{Cl}$ & p Value \\
\hline \multicolumn{4}{|l|}{ Total mortality } \\
\hline Platelet count $>400 \times 10^{9}$ cells $/ \mathrm{mm}^{3}$ & 1.53 & 1.03 to 2.29 & 0.030 \\
\hline Age & 1.02 & 1.01 to 1.04 & 0.0007 \\
\hline Congestive cardiac failure & 1.52 & 1.11 to 2.10 & 0.009 \\
\hline Neoplastic disease & 2.65 & 1.78 to 3.96 & $<0.0001$ \\
\hline MRC dyspnoea score & 1.81 & 1.54 to 2.13 & $<0.0001$ \\
\hline Long term oxygen therapy & 1.66 & 1.09 to 2.55 & 0.021 \\
\hline Acidosis during exacerbation & 2.15 & 1.53 to 3.03 & $<0.0001$ \\
\hline Antiplatelet therapy & 0.60 & 0.43 to 0.83 & 0.002 \\
\hline \multicolumn{4}{|c|}{ Hosner-Lemeshow goodness of fit test $p=0.676$} \\
\hline \multicolumn{4}{|l|}{ Inhospital mortality } \\
\hline Platelet count $>400 \times 10^{9}$ cells $/ \mathrm{mm}^{3}$ & 2.37 & 1.29 to 4.34 & 0.005 \\
\hline Age & 1.03 & 1.01 to 1.06 & 0.030 \\
\hline Congestive cardiac failure & 1.75 & 1.06 to 2.91 & 0.034 \\
\hline Neoplastic disease & 1.79 & 1.00 to 3.24 & 0.048 \\
\hline Acidosis & 5.24 & 3.16 to 8.68 & $<0.0001$ \\
\hline $\begin{array}{l}\text { BAP-65 } \\
\text { Hosner-Lemeshow goodness of fit tes }\end{array}$ & 1.82 & 1.37 to 2.43 & $<0.0001$ \\
\hline \multicolumn{4}{|l|}{ Mortality after discharge } \\
\hline Platelet count $>400 \times 10^{9}$ cells $/ \mathrm{mm}^{3}$ & 1.30 & 0.82 to 2.06 & 0.261 \\
\hline Age & 1.02 & 1.00 to 1.03 & 0.024 \\
\hline Congestive cardiac failure & 1.60 & 1.06 to 2.39 & 0.022 \\
\hline Neoplastic disease & 2.48 & 1.60 to 3.82 & $<0.0001$ \\
\hline MRC dyspnoea score & 2.06 & 1.73 to 2.46 & $<0.0001$ \\
\hline Long term oxygen therapy & 1.64 & 1.04 to 2.60 & 0.030 \\
\hline Antiplatelet therapy & 0.59 & 0.43 to 0.81 & 0.001 \\
\hline Resident in long term care facility & 2.21 & 1.17 to 4.19 & 0.015 \\
\hline \multicolumn{4}{|c|}{ Hosner-Lemeshow goodness of fit test $p=0.502$} \\
\hline
\end{tabular}

to $0.85, \mathrm{p}=0.003)$ ) but was not significantly associated with inhospital mortality (OR 0.69 (95\% CI 0.41 to 1.11, $\mathrm{p}=0.124)$ ). Mortality was significantly increased in patients who survived to hospital discharge up to 1 year (OR 0.62 (95\% CI 0.46 to $0.85, \mathrm{p}=0.003)$ ). The relationship between antiplatelet therapy and cardiovascular hospitalisation (OR 0.73 (95\% CI 0.50 to $1.06, \mathrm{p}=0.097)$ ) and cardiovascular death (OR 0.77 $(0.47-1.28, \quad p=0.311)$ ) was not statistically significant. To explore whether the apparent benefit observed was an antiplatelet or anticoagulant effect, warfarin was also assessed $(n=98)$ with no significant difference in 1-year overall mortality (OR $0.96(95 \%$ CI 0.56 to $1.63, \mathrm{p}=0.877)$ ).

\section{Systemic inflammatory markers and outcomes}

There was a weak correlation between white cell and platelet counts $(R=0.158, p<0.0001)$. CRP showed no significant
Table 4 Antiplatelet therapy and outcomes: logistic regression analyses

\begin{tabular}{|c|c|c|c|}
\hline Predictor & OR & $95 \% \mathrm{Cl}$ & $\mathrm{p}$ Value \\
\hline \multicolumn{4}{|l|}{ Total mortality } \\
\hline Antiplatelet therapy & 0.63 & 0.47 to 0.85 & 0.003 \\
\hline Age & 1.02 & 1.00 to 1.03 & 0.032 \\
\hline Neoplastic disease & 2.44 & 1.63 to 3.67 & $<0.0001$ \\
\hline MRC dyspnoea score & 1.83 & 1.56 to 2.16 & $<0.0001$ \\
\hline Long term oxygen therapy & 1.70 & 1.10 to 2.62 & 0.016 \\
\hline Residence in long term care facility & 2.54 & 1.42 to 4.54 & 0.002 \\
\hline Acidosis & 1.93 & 1.36 to 2.74 & 0.0002 \\
\hline \multicolumn{4}{|c|}{ Hosner-Lemeshow goodness of fit test $p=0.687$} \\
\hline \multicolumn{4}{|l|}{ Inhospital mortality } \\
\hline Antiplatelet therapy & 0.69 & 0.41 to 1.11 & 0.124 \\
\hline Age & 1.03 & 1.00 to 1.05 & 0.046 \\
\hline Neoplastic disease & 1.91 & 1.06 to 3.45 & 0.030 \\
\hline Acidosis & 5.19 & 3.14 to 8.58 & $<0.0001$ \\
\hline BAP-65 & 1.82 & 1.37 to 2.42 & $<0.0001$ \\
\hline \multicolumn{4}{|c|}{ Hosner-Lemeshow goodness of fit test $p=0.957$} \\
\hline \multicolumn{4}{|l|}{ Mortality after discharge } \\
\hline Antiplatelet therapy & 0.62 & 0.46 to 0.85 & 0.003 \\
\hline Age & 1.02 & 1.01 to 1.03 & 0.014 \\
\hline Neoplastic disease & 2.30 & 1.47 to 3.59 & 0.0003 \\
\hline MRC dyspnoea score & 1.99 & 1.66 to 2.38 & $<0.0001$ \\
\hline Long term oxygen therapy & 1.73 & 1.08 to 2.76 & 0.022 \\
\hline Residence in long term care facility & 2.16 & 1.14 to 4.09 & 0.018 \\
\hline \multicolumn{4}{|c|}{ Hosner-Lemeshow goodness of fit test $p=0.600$} \\
\hline
\end{tabular}

correlation with platelet count $(p=0.5)$. After adjustment for confounders in a logistic regression model, CRP was not associated with either total 1-year mortality (OR 1.01 95\% CI 0.98 to 1.04 per $10 \mathrm{mg} / \mathrm{L}$ increment, $\mathrm{p}=0.455)$ or inhospital mortality (OR $1.0395 \%$ CI 0.99 to 1.08 , per $10 \mathrm{mg} / \mathrm{L}$ increment, $\mathrm{p}=0.107)$. There was no relationship between CRP and cardiovascular events (OR $1.01(0.97-1.03, \mathrm{p}=0.912)$ ). This was not affected by entering CRP as a categorical variable using prespecified cut-offs $(>50 \mathrm{mg} / \mathrm{L}$ or $100 \mathrm{mg} / \mathrm{L}$, data not shown).

Similarly, white blood cell count was not an independent predictor of either total 1-year mortality (OR 0.98 (95\% CI 0.95 to 1.01 ), $\mathrm{p}=0.222$ ) or inhospital mortality (OR 0.95 (95\% CI 0.89 to 1.01$), p=0.087)$. There was no relationship between WCC and cardiovascular events (OR 1.00 (95\% CI 0.98 to 1.02$), p=0.854)$. Entering white blood cell count as a categorical variable using prespecified cut-offs $\left(>12 \times 10^{9}\right.$ cells/ $\mathrm{mm}^{3}$ or $>15 \times 10^{9}$ cells $/ \mathrm{mm}^{3}$ ) also did not identify a statistically significant relationship with any of the outcomes (data not shown).
Figure 2 Kaplan-Meier survival curve comparing the thrombocytosis and normal platelet groups. Curve comparison by log-rank test, $\mathrm{p}=0.009$ for thrombocytosis versus normal platelet counts, $p=0.09$ for antiplatelet users versus non-users.
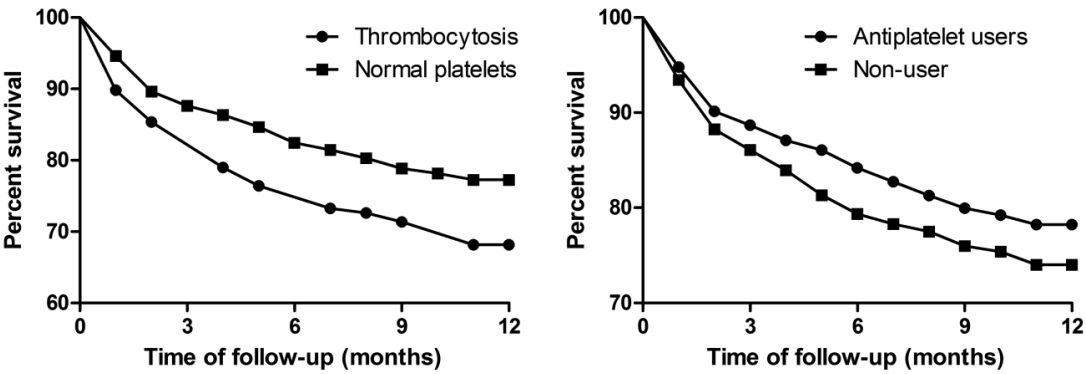


\section{DISCUSSION}

Our data demonstrate thrombocytosis is associated with significantly increased 1-year mortality following admission with AECOPD. Thrombocytosis was associated with significantly increased inhospital mortality and correlated with markers of type II respiratory failure and exacerbation severity. Thrombocytosis was not associated with chronic comorbidities such as ischaemic heart disease, diabetes or renal impairment.

As with all association studies, our data cannot prove causation and the underlying mechanisms between thrombocytosis and death are not clear. McDonald et al demonstrated that 14 days of hypoxia resulted in thrombocytosis, and hypothesised that 'shedding' of immature platelets from megakaryocytes was the mechanism. ' This hypothesis is supported by Wedzicha et al who established a negative correlation between mean platelet volume (MPV) and arterial oxygen tension, ${ }^{10}$ given that immature reticulated platelets have a larger MPV than mature circulating platelets. Larger, immature platelets have also been shown to be more haemostatically active than mature platelets, ${ }^{20}$ which may also explain the increased platelet aggregation found in hypoxaemic COPD patients, ${ }^{11}$ and increased platelet activation in patients with AECOPD. ${ }^{12}$ In our cohort, respiratory failure is also indicated as an important factor in the association between thrombocytosis and increased mortality. Baseline characteristics were very similar between groups although there was a small difference in the frequency of LTOT prescription comparing the thrombocytosis and normal platelet groups. Similarly, the most striking differences between the nature of acute exacerbation pertain to acute ventilatory failure with thrombocytosis patients more likely to be hypoxic, hypercapnic or receive non-invasive ventilation. While acute respiratory acidosis is a strong predictor of mortality in AECOPD, ${ }^{21}$ the effect of thrombocytosis was independent of this, suggesting that patient specific haematological responses to hypoxia and respiratory failure may be more important than previously recognised. This individualised response to infection or another exacerbation trigger may mark out patients more likely to have a pro-inflammatory response to subsequent exacerbations and explain the observed increase in all-cause mortality.

Given the known association between ischaemic heart disease and COPD, ${ }^{22-24}$ we expected thrombocytosis to be strongly associated with cardiac comorbidity and mortality. Hypoxic pulmonary vasoconstriction with increase in cardiac afterload, strain on the right ventricle and sequential tachycardia has been postulated as an additional mechanism for arrhythmia and cardiovascular events. ${ }^{24}$ Despite this, we did not demonstrate a significant increase in cardiac hospitalisations and death. It is therefore difficult to propose cardiac disease as the key mechanism to explain excess morbidity and mortality seen with thrombocytosis and supports a mechanism more closely related to hypoxia and inflammation. In our study, CRP, another common inflammatory marker, was not correlated with an increase in mortality. Similarly, previous studies exploring CRP as a possible marker of severity and mortality in AECOPD have been equivo$\mathrm{cal}^{25}{ }^{26}$ It may be that platelet responses and CRP represent different aspects of the inflammatory response. The finding that acute changes in platelet count during AECOPD are associated with increased 1-year all-cause mortality suggests that the process is more complex than an acute inflammatory insult. The ECLIPSE cohort (Evaluation of COPD Longitudinally to Identify Predictive Surrogate Endpoints) demonstrated the complexity of chronic inflammation in COPD, and brought home the concept of persistent systemic inflammation during periods of stability. ${ }^{27}$ It may be that acute haematological responses are more important to long term inflammation than more commonly recognised acute phase proteins such as CRP.

In the whole cohort, patients on antiplatelets had a significant reduction in 1-year mortality that again was not solely attributable to a reduction in cardiovascular events. In observational studies, there is always potential that a signal is due to the 'healthy user effect', even when analyses adjusted for comorbidities. We regard this explanation as unlikely since antiplatelet therapies are generally prescribed for cardiovascular and cerebrovascular diseases which are associated with increased mortality, and therefore the effect of antiplatelets may be potentially underestimated. $^{28}$ When combined with recent data highlighting the importance of other cardiovascular treatments in COPD, and particularly $\beta$-blockers, ${ }^{29} 30$ there is a growing argument that physicians should be seeking and treating cardiovascular risk in COPD. Large scale randomised control trials in antiplatelets are warranted as they may prove a role for inexpensive therapies with considerable benefits in COPD.

To our knowledge, this is the first prospective study to examine thrombocytosis in AECOPD. EXODUS is a large, multi-centre database with similar demographics to that of the 2008 national BTS audit ${ }^{31}$ and we therefore feel that the results should be generalisable to other populations. Nonetheless, we must acknowledge several limitations. It is an observation and therefore prone to the inherent weaknesses of this type of study. ICD-10 codes were used and are known to have limitations in accuracy. In particular, we used death certification to classify mortality as cardiovascular or non-cardiovascular which may have modest accuracy. ${ }^{32}$ However, this method has been well used in similar studies and any inaccuracy is likely to be similar in both the thrombocytosis and normal platelet group. Another potential weakness is that data were only recorded from the day of admission. It would have been desirable to have serial platelet counts to assess whether thrombocytosis was transient, related only to that admission or whether there were persistent or recurrent abnormalities in platelet counts. The association of thrombocytosis with outcome was independent of neoplastic disease suggesting that this was an effect of exacerbations of COPD, rather than due to neoplastic disease or haematological malignancy. Thrombocytosis was significantly associated with outcome even after exclusion of patients with very high platelet counts further strengthening this conclusion. Although it would be useful to have included more detailed assessment of platelet and clotting function rather than the crude numbers, platelet count is readily available to all clinicians on a day-to-day basis. We also did not follow-up medication use, and therefore cannot guarantee that all patients who were on antiplatelets on admission were still prescribed them throughout the study. The reasons for discontinuation of antiplatelet agents are few, however, and we hypothesise that this may only have been a very small number of patients and unlikely to have affected our results. Finally, while the observation of apparent risk reduction associated with platelet therapy is of great interest, randomised controlled trials would be required to confirm or refute its usefulness in patients suffering from AECOPD.

\section{CONCLUSIONS}

In AECOPD, thrombocytosis is associated with increased mortality. Acute type II respiratory failure and LTOT were more common in patients with thrombocytosis, though other severity markers were similar. These results suggest platelets may have an important inflammatory role in COPD, possibly related to hypoxia. In all patients, antiplatelet medications were associated 
with significantly lower 1-year mortality and may have a protective role to play in patients with AECOPD.

Acknowledgements We thank Ashan R Akram, University of Edinburgh; Ross Archibald, University of Dundee; Louise Peet, University of Dundee; Charly Sengheiser, Doncaster Royal Infirmary; Duneesha De Fonseka, Doncaster Royal Infirmary; Gillian B Fleming, Edinburgh Royal Infirmary; Hazel Rooney, Perth Royal Infirmary; Duncan Mills, Royal Infirmary of Edinburgh; Sarah Higgins, Doncaster Royal Infirmary; John Corcoran, John Radcliffe Hospital, Oxford; Joseph Hodgson, NHS Tayside; Martin K Smith, NHS Borders; and Mudher Al-Khairalla, Doncaster Royal Infirmary, for their help with data collection.

Contributors MTH was responsible for study conception, design, data collection and data analysis. PS, PW and AS were responsible for data collection and data analysis. JDC was involved in the study design, data collection and data analysis. SS was involved in study design and data analysis. All authors contributed to drafting the manuscript and approved manuscript prior to submission. All authors had full access to all of the data in the study and can take responsibility for the integrity of the data and the accuracy of the data analysis. JDC is the study guarantor.

Competing interests None.

Ethics approval South East Scotland research ethics committee.

Provenance and peer review Not commissioned; externally peer reviewed.

\section{REFERENCES}

1 Lozano R, Naghavi M, Foreman K, et al. Global and regional mortality from 235 causes of death for 20 age groups in 1990 and 2010: a systematic analysis for the Global Burden of Disease Study 2010. Lancet 2012;380:2095-128.

2 Ross R. Atherosclerosis—an inflammatory disease. N Engl I Med 1999:340:115-26.

3 Holguin F, Folch E, Redd SC, et al. Comorbidity and mortality in COPD-related hospitalizations in the United States, 1979 to 2001. Chest 2005;128:2005-11.

4 Incalzi RA, Caradonna P, Ranieri P, et al. Correlates of osteoporosis in chronic obstructive pulmonary disease. Respir Med 2000;94:1079-84.

5 Donaldson GC, Hurst JR, Smith CJ, et al. Increased risk of myocardial infarction and stroke following exacerbation of COPD. Chest 2010;137:1091-7.

6 Furie B, Furie BC. Thrombus formation in vivo. I Clin Invest 2005;115:3355-62.

7 Tabuchi $A$, Kuebler WM. Endothelium-platelet interactions in inflammatory lung disease. Vascul Pharmacol 2008:49:141-50.

8 Gawaz M, Langer H, May AE. Platelets in inflammation and atherogenesis. Clin Invest 2005:115:3378-84.

9 McDonald TP, Cottrell M, Clift R. Effects of short-term hypoxia on platelet counts of mice. Blood 1978:51:165-75.

10 Wedzicha JA, Cotter FE, Empey DW. Platelet size in patients with chronic airflow obstruction with and without hypoxaemia. Thorax 1988;43:61-4.

11 Wedzicha JA, Syndercombe-Court D, Tan KC. Increased platelet aggregate formation in patients with chronic airflow obstruction and hypoxaemia. Thorax 1991:46:504-7.

12 Furman MI, Benoit SE, Barnard MR, et al. Increased platelet reactivity and circulating monocyte-platelet aggregates in patients with stable coronary artery disease. J Am Coll Cardiol 1998;31:352-8.

13 Maclay JD, McAllister DA, Johnston $S$, et al. Increased platelet activation in patients with stable and acute exacerbation of COPD. Thorax 2011;66:769-74.
14 Huiart L, Ernst P, Suissa S. Cardiovascular morbidity and mortality in COPD. Chest 2005; 128:2640-6.

15 Sidney S, Sorel M, Quesenberry CP, et al. COPD and incident cardiovascular disease hospitalizations and mortality: Kaiser Permanente Medical Care Program. Chest 2005;128:2068-75

16 Stone IS, Petersen SE, Barnes NC. Raised troponin in COPD: clinical implications and possible mechanisms. Heart 2013;99:71-2.

17 Schembri S, Williamson PA, Short PM, et al. Cardiovascular events after clarithromycin use in lower respiratory tract infections: analysis of two prospective cohort studies. BMJ 2013:346:f1235.

18 Lange P, Marott JL, Vestbo J, et al. Prediction of the clinical course of Chronic Obstructive Pulmonary Disease using the new GOLD classification: a study of the general population. Am J Respir Crit Care Med 2012;186:975-81.

19 Shorr AF, Sun X, Johannes RS, et al. Validation of a novel risk score for severity of illness in acute exacerbations of COPD. Chest 2011;140:1177-83.

20 Thompson CB, Eaton KA, Princiotta SM, et al. Size dependent platelet subpopulations: relationship of platelet volume to ultrastructure, enzymatic activity, and function. Br I Haematol 1982;50:509-19.

21 Roberts CM, Stone RA, Buckingham RJ, et al. National Chronic Obstructive Pulmonary Disease Resources and Outcomes Project implementation group. Acidosis, non-invasive ventilation and mortality in hospitalised COPD exacerbations. Thorax 2011;66:43-8.

22 Sin DD, Man SF. Chronic obstructive pulmonary disease as a risk factor for cardiovascular morbidity and mortality. Proc Am Thorac Soc 2005;2:8-11.

23 de Lucas-Ramos P, Izquierdo-Alonso JL, Rodriguez-Gonzalez-Moro JM, et al. Chronic obstructive pulmonary disease as a cardiovascular risk factor. Results of a case-control study (CONSISTE study). Int I Chron Obstruct Pulmon Dis 2012;7:679-86.

24 Chang CL, Robinson SC, Mills GD, et al. Biochemical markers of cardiac dysfunction predict mortality in acute exacerbations of COPD. Thorax 2011;66:764-8.

25 Man P, Connett JE, Anthonisen NR, et al. C-reactive protein and mortality in mild to moderate chronic obstructive pulmonary disease. Thorax 2006;61:849-53.

26 Antonescu-Turcu AL, Tomic R. C-reactive protein and copeptin: prognostic predictors in chronic obstructive pulmonary disease exacerbations. Curr Opin Pulm Med 2009;15:120-5.

27 Agustí A, Edwards LD, Rennard SI, et al. Evaluation of COPD Longitudinally to Identify Predictive Surrogate Endpoints (ECLIPSE) Investigators. Persistent systemic inflammation is associated with poor clinical outcomes in COPD: a novel phenotype. PLoS One 2012;7:e37483.

28 Eurich DT, Marrie TJ, Johnstone J, et al. Mortality reduction with influenza vaccine in patients with pneumonia outside "flu" season: pleiotropic benefits or residual confounding? Am J Respir Crit Care Med 2008; 178:527-33.

29 Short PM, Lipworth $\mathrm{Sl}$, Elder $\mathrm{DH}$, et al. Effect of beta blockers in treatment of chronic obstructive pulmonary disease: a retrospective cohort study. BMJ 2011;342: d2549.

30 Rutten FH, Zuithoff NPA, Hak E, et al. Beta-blockers may reduce mortality and risk of exacerbations of patients with Chronic Obstructive Pulmonary Disease. Arch Intern Med 2010;170:880-7.

31 Royal College of Physicians of London, British Thoracic Society and British Lung Foundation. Report of the National Chronic Obstructive Pulmonary Disease Audit 2008: clinical audit of COPD exacerbations admitted to acute NHS units across the UK. Nov 2008. http://www.brit-thoracic.org.uk/Portals/0/Clinical\%20Information/ COPD/NCROP/NCROPClinicalAudit.pdf (accessed Jun 2013).

32 Drummond MB, Wise RA, John M, et al. Accuracy of death certificates in COPD: analysis from the TORCH trial. COPD 2010;7:179-85. 